\title{
Major risks associated with the renovation of Terminal Building 2, Cairo International Airport, Egypt
}

\author{
S. Noureldin, I. Eshra \& M. ElTabbaa \\ ECG Engineering Consultants Group S.A., Cairo, Egypt
}

\begin{abstract}
Cairo Airport Company (CAC) is in the process of fully renovating Terminal Building 2 (TB2), Cairo International Airport, Egypt. The total built-up area of the renovation project is $168,000 \mathrm{~m}^{2}$ approximately that comprises the renovation of the existing building and landside area, as well as the construction of new buildings that include a new departure building and airside pier. Due to the design requirements and the construction conditions accompanied by the brown field site with demolition, refurbishment, pollution, as well as being in the heart of the airport and bounded by other prestigious ongoing construction projects, it was obligatory to implement a risk management system which shall be used to substantially manage the risks as the project progresses. A systematic approach was utilized to identify and asses the project's risks for different risks categories including external, environmental, project management, construction, and engineering services risks. Control measures had been proposed and contingency budget was allocated for risk treatment in case of occurrence.
\end{abstract}

Keywords: risk management, airport design, brown fields, re-development, renovation.

\section{Introduction}

Cairo International Airport has three (3) existing terminals and a fourth one is under tendering / construction. The four (4) terminals are as follows [1]:

- Terminal Building One (TB1), serving foreign carriers of a capacity estimated 8.4 Million Annual Passengers (MAP) as per the year 2007 statistics. TB1 and was constructed in 1963. 
- Terminal Building Two (TB2), serving Arabian carriers of a capacity estimated at 3.8 MAP as per the year 2007 statistics. TB2 was constructed in 1986.

- Terminal Building Three (TB3), serving EgyptAir and Star Alliance Group and is of a design capacity estimated at 11 MAP. TB3 construction was completed in 2008.

- Terminal Building Four (TB4), serving Seasonal Flights with capacity of 1.5 MAP, and is expected to be opened in 2011.

After the completion of Terminal Building Three (TB3), Cairo Airport Company (CAC) planned to refurbish TB2. An engineering group constituting of Engineering Consultants Group S.A. (ECG) of Cairo, Egypt and Netherlands Airport Consultants (NACO) of the Hague, the Netherlands, developed different scenarios related to the renovation strategy. The results of the study were presented to the CAC in the year 2008. TB2 capacity upgrade to 7.5 MAP scenario has been selected by CAC, and was further developed by the Consultant (ECG/NACO), and is now under tendering.

\section{Existing conditions at TB2}

The existing (TB2) was opened in 1986, and was designed to serve the primarily European, Far Eastern and the Gulf region airlines (Figure 1). The operational capacity of the terminal building was approximately 3.8 MAP in 2007, and the actual peak-hour capacity was limited to 3 (three) simultaneous flights, which is approximately 1,000 passengers/hour. The upgrade of the terminal facilities to enhance the capacity and the building standard was considered necessary and was planned to commence after the completion of the new TB3. TB3 is linked by a connecting bridge to the facilities of TB2. The impression of the airport since the completion of TB3 has changed considerably due to different architectural styles of TB3.

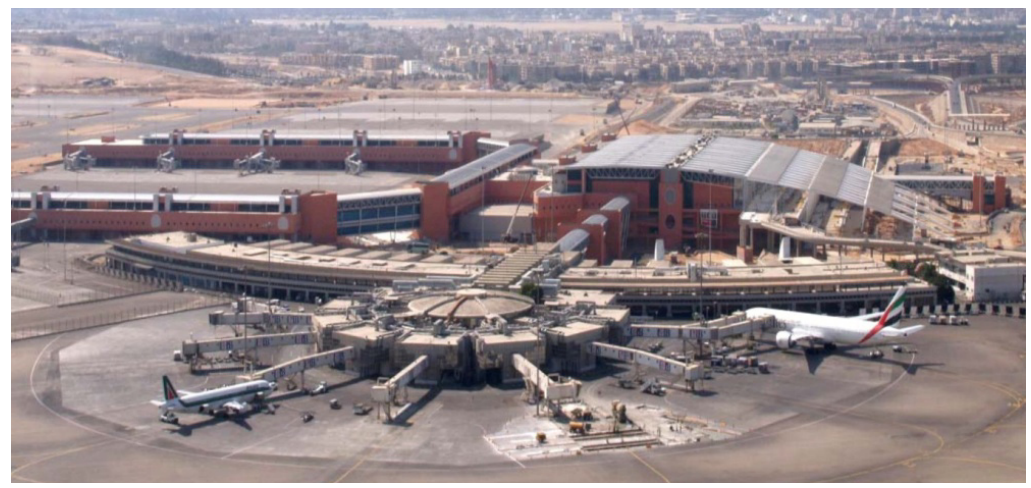

Figure 1: $\quad$ TB2 (foreground) and TB3 (background). 


\section{One roof concept}

CAC's requirements to operate TB2 from TB3 as "One Terminal", has been used to translate this into a "One Roof" concept (Figure 2). This "One Roof" concept is expressed by using the same architectural defining elements of TB3 for the check-in hall of TB2. The V-formed steel construction and the sun shadow system of TB3 have been adopted for TB2 as the defining architectural element. The existing curb of TB2 functioned as a natural separation between both terminals. The renovated terminal building will provide fourteen (14) fixed bridge access to apron stands and four remote stands. Seventy-five percent $(75 \%)$ of the aircraft stands will be contact stands while the remaining twentyfive percent $(25 \%)$ of the stands will be remote. Two parallel taxiways serve the apron bay. The terminal building size is based on an International Air Transport Association (IATA) level of service B [2]. The design peak hour is estimated at 3,150 ( 2 way) international passengers. The link connection between TB2 and TB3 shall remain and shall be used concurrently with TB3, thus, maintaining simultaneous passenger services at both terminals. All taxiways and aircraft are laid out for unrestricted use of code $\mathrm{E}$ and partly for code $\mathrm{F}$ aircrafts. The traffic characteristic for the new passenger terminal is $100 \%$ international traffic. A maximum of $15 \%$ transfer has been taken into consideration.

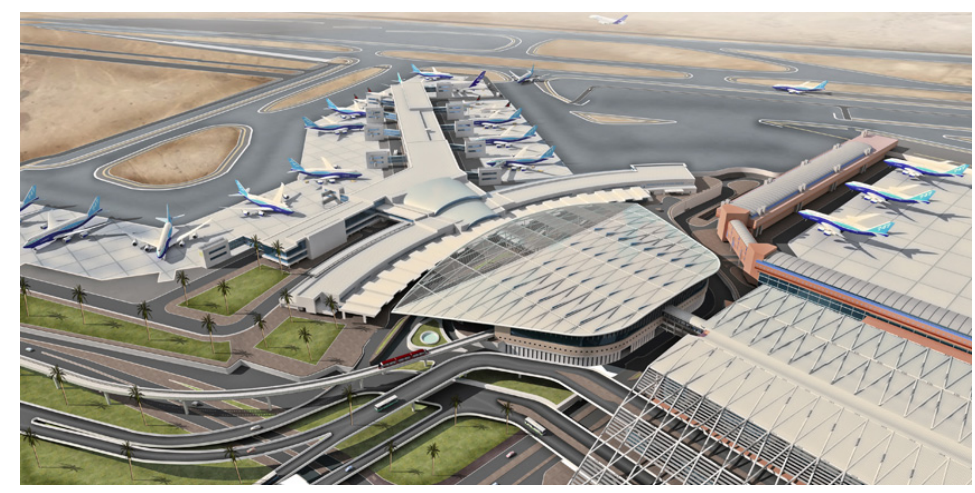

Figure 2: $\quad$ One roof concept [3].

\section{Challenges related to the renovation program}

Among other activities and project in the surrounding zone of the airport, three (3) major projects have had to be considered during the design and construction of the renovation project of TB2. Those three projects are: Automated People Mover (APM), Cairo Airport Cargo City (CCC), and Cairo Airport New Hotel (AIROTEL).

\subsection{Automated people mover}

The existing three terminal buildings (TB1, TB2 ant TB3) at Cairo International Airport are located so that TB1 is at a distance from TB2 and TB3, while TB3 
was connected integrally with TB2 via a skyway bridge composed of three levels; two (2) of which are airside while the third is landside and open to air. The three terminals are intended to be connected together via an automated people mover, to transfer passengers between both airside and landside of the three terminals. Furthermore it will connect the terminals to the new multi-story garage of 4000 cars capacity. The APM shall be capable to transfer 1200 persons per hour between the three terminals. TB4, which shall serve seasonal flights, shall not be connected to the APM transit system.

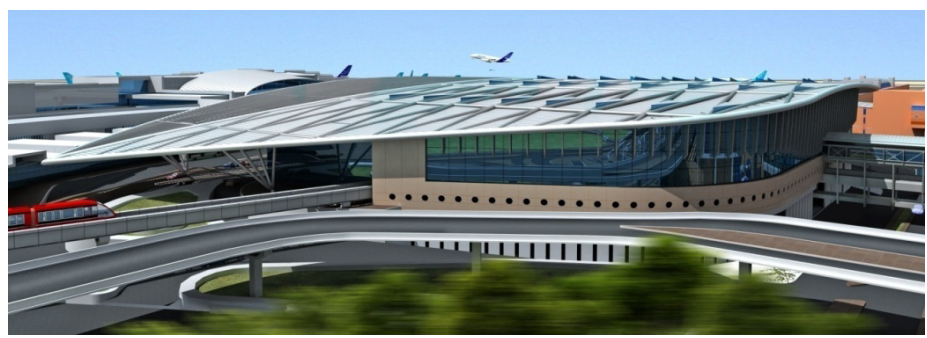

Figure 3: $\quad$ View of the new departure hall of TB2, APM station [3].

The optimum location for the APM station at TB2 and TB3 was agreed to be at the skyway bridge link between TB2 and TB3 (Figure 3). This location shall allow the passengers to move easily from/to the airside and landside of both terminals: TB2 and TB3. That location lies exactly in the heart of the new departure building of the renovated TB2. The design coordination between the two separate design teams of the two projects was extensively made by virtue of review/coordination workshops and technical meetings attended by large number and different levels of engineering teams. The design of both projects had to be coordinated and modified to allow for compatibility in the construction stage as well as during the operation stage. Architectural space program and arrangement were modified. Structural and foundations were coordinated. Electromechanical works were also coordinated, including HVAC, fire fighting, lighting, elevators / escalators and special security and communication systems. The designs were successfully developed so that the construction contractor of the APM project will complete his scope to construct the station as a completed closed box, then the renovation of TB2 construction contractor shall receive the closed box station and after completion of his scope, he shall peel-out the closed box station, so that the station shall be finally operating as a part of the internal areas of the departure building. The risk therefore was considered to be high in both the design stage for in-compatibility and the construction stage for miss-matching and damaging the scope of other project.

\subsection{Cargo City Cairo}

The airside of TB2 has an east side border with the proposed Cairo Airport Cargo City (CCC) that will raise the capacity of Cairo Airport cargo business to more than one million tons annually (Figure 4). The CCC area is about 
$180,000 \mathrm{~m}^{2}$ and has direct access to both landside and airside. Coordinated designs of both projects (TB2 and CCC) were essential to achieve proper match line of both projects as well as to achieve a well interfaced access way between the CCC and the renovated apron of TB2.

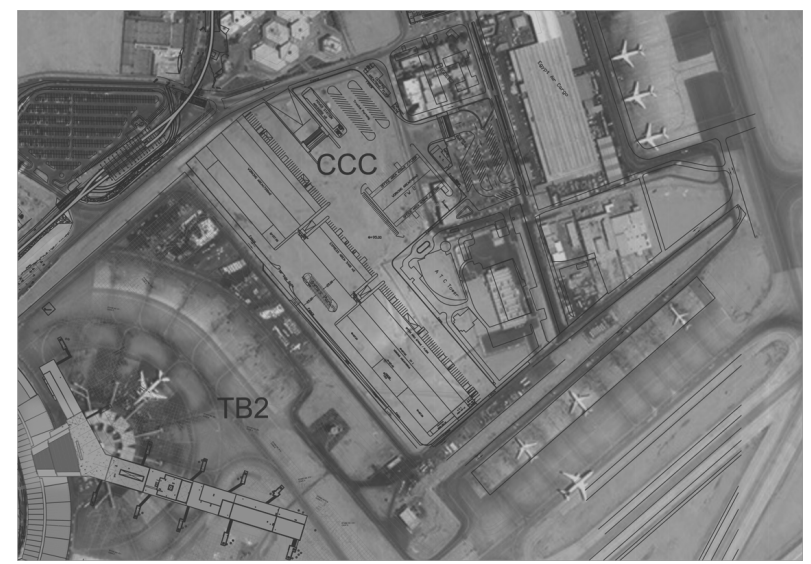

Figure 4: The location of CCC project.

Design workshop sessions were conducted to define the coordinated finished levels, boundaries bench marks of both projects and to minimize construction activities contradictions. Both projects' construction activities are planned to start by the end of 2010, while the construction durations of both projects are expected to be 30 months.

\subsection{Cairo Airport Hotel (AIROTEL)}

The new hotel at Cairo Airport shall be connected to the recently opened TB3 (Figure 5). The connection is direct via a landside link bridge, so that a passenger

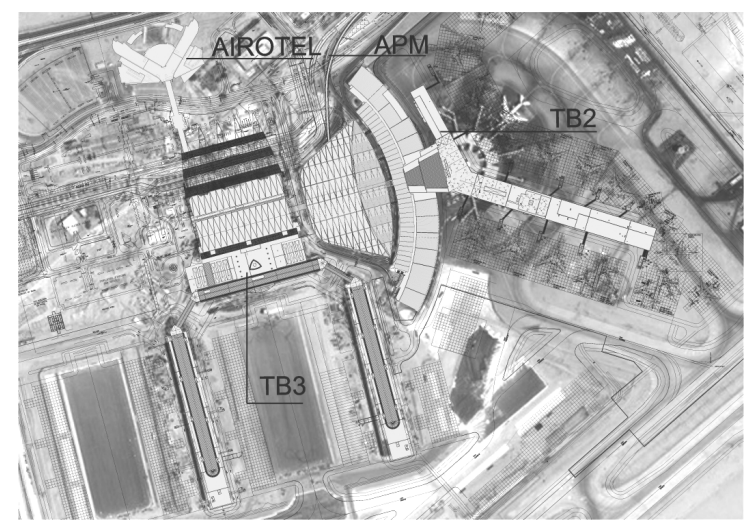

Figure 5: The location of the Airotel project. 
can walk with his baggage cart to the hotel lobby. The construction of the hotel had started already in 4Q2009. The impact of heavy construction traffic of the hotel had to be considered during developing the designs of TB2 for a proper planning of the construction activities, by preparing a well planned traffic management layout. Through discussions and workshop session between the owner, the engineer and the construction contractor, a well defined route map and contractor's camp facilities were agreed upon, which is anticipated to minimize the intersection between the construction fleet traffic of both projects, not to ignore the normal daily traffic to and from TB3 and the surrounding airport areas.

\section{Objectives of the risk management plan}

The project risk management process helps project stakeholders and the project team makes informed decisions regarding alternative approaches to achieving their objectives and the relative risk involved in each, in order to increase the likelihood of success in meeting or exceeding the most important objectives [4, 5] especially in the presence of untraditional coordination activities between simultaneous important projects. Risk management encourages the project team to take appropriate measures to:

- Minimize adverse impacts to project scope, cost, and schedule (and quality, as a result).

- Maximize opportunities to improve the project's objectives with lower cost, shorter schedules, enhanced scope and higher quality.

- Minimize management by crisis, which was a prevailing approach several years ago in managing projects in the Middle East.

\section{Risk management strategy}

Being TB2 Renovation Program Project Manager, ECG/ NACO has been assigned by the Egyptian Holding Company for Airports and Air navigation (EHCAAN) and CAC for administering risk management processes and activities for the Project. Throughout all phases of the project, risks monitoring and identification shall be a regular topic of discussion. The intent is to instruct the project team in the need for risk awareness, identification, documentation and communication. ECG/NACO identified and documented known risk factors during the creation of the Risk Register. Updates to the risk register will occur as risk exposure change. Additionally, risk management will be a topic of discussion during the monthly project meeting during the construction phase. TB2 Renovation Program Project team will discuss any new risk factors or events. New risks shall be reviewed with CAC and EHCAAN's Project Management Unit (PMU). The Risk Manager is responsible for logging the risk to the Risk Register. Notification of a new risk should include the following Risk Register elements:

- Description of the risk factor or event, e.g. conflicting project or operational initiatives that place demands on project resources, design errors or 
omissions, weather, construction delays, etc.

- Probability that the event will occur. For example, a 50\% chance that the vendor will not have staff available to carry part of the Works.

- Schedule Impact. The delay by which a risk factor could impact the schedule.

- Scope Impact. The impact the risk will have on the envisioned accomplishments of the project. Extreme weather conditions may result in reducing the construction works productivity.

- Quality Impact. A risk event may result in a reduction in the quality of work or products that are developed. As an example, lack of funding caused by construction cost overruns may result in omitting some of the project's elements.

- Cost Impact. The impact the risk event is likely to have on the project budget.

\section{Risk assessment}

Risk assessment typically involves input from all of project management functions [6]. Consequently, a major benefit of risk management, particularly early on in the project, is the integrating and team-building effect experienced by members of the project team. Risk assessment is the act of determining the probability that a risk will occur and the impact that event would have should it occur. This is basically a "cause and effect" analysis. In TB2 Project, the assessment of a risk involves two factors. First is the probability which is the measure of certainty that an event, or risk, will occur. The probability shall be measured as a percentage that ranges from $1 \%$ to $100 \%$. A risk with no probability of occurring will obviously pose no threat, while a risk of $100 \%$ means the risk event has occurred. The second factor is estimating the impact on the project. This shall be a somewhat subjective assessment, but had been quantified whenever possible. The estimated cost, the duration of the potential delay, the changes in scope and the reduction in quality are in most cases factors that can be estimated and documented in the risk statement and then measured using the standard project management tools (i.e. project plan, budget, statements of work, etc.). In this study, the Risk Register contains five ratings for impact, very high, high, medium, low and insignificant. This approach is straightforward for comparing one risk to another and assigns priorities. For each of the impact categories the impact is assessed as follows:

- Cost: This impact is usually estimated as the amount of additional cost that has a direct impact to the project's budget.

- Scope: Whenever there is a potential that the final product will not be completed as originally envisioned there is a scope impact. Scope impact could be measured as a reduction in the project's built-up area or capacity, reduction in aircraft stands, etc.

- Schedule: It is very important to estimate the schedule impact of a risk event as this often results is the basis for elevating the other impact categories. Schedule delays frequently result in cost increases and may result in a reduction of scope or quality. As an example, the construction of the new 
departure hall is scheduled to commence after the APM TB2/3 station construction completion. In case that a delay is encountered in the APM $\mathrm{TB} 2 / 3$ station construction completion date, the final completion date of the TB2 project will be affected.

- Quality: mitigation strategies that rely upon a reduction in quality should be approved by the project owner/ sponsor and recorded in the risk register, in order not to cause disappointment to the project's stakeholders.

\section{Risk probability evaluation}

The following scale is used to evaluate the probability of the risk event(s) occurring: probability of $60-99 \%, 40-59 \%, 20-39 \%, 10-19 \%$, and $1-19 \%$ are corresponding to almost certain, likely, possible, unlikely and rarae (from 1-5 scoring) respectively.

Each identified risk is assessed based on the following:

- Probability of occurring, rated 1 to 5 , based on the risk probability ranking. The probability remains the same for all four objectives (cost, time, scope and quality) of a risk.

- Impact is rated separately for each objective (cost, time, scope and quality) based on the evaluating impact of a risk on major project objectives.

The output of this calculation is, for each risk, a probability and up to four (4) impacts corresponding to the objectives that the risk would impact.

\section{Risk impact assessment}

The impact of the risk, should it occur, needs to be considered in time, cost and quality terms, as follows:

- Cost/ Budget: the impact on claim in terms of unit currency

- Timescale: the impact on project programme in terms of unit time

- Project Scope: the impact on the project's features in terms of $\mathrm{m}^{2}$ space, capacity, efficiency, etc.

- Project Quality: the impact on Safety, Constructionabilty, Operability, and Maintainability.

A large emphasis on mitigating risks with high or very high impacts approach shall be adopted. For this purpose a greater-than-linear weight to impact levels shall be provided, for major project objectives $[4,5]$. The greater-than-linear scores higher impacts may apply to any or all objectives - hence it is likely that different objectives may have different scoring systems applied to them. For each impact type, likely effect shall be rated and scored as per Table 1 .

The impact score will be a value between 4 and 20. In order to quantify the importance of a risk factor in the categories defined above, the impact against four (4) axes is assessed using the impact matrix as shown in Table 2 [5]. 
Table 1: $\quad$ Impact scoring [5].

\begin{tabular}{|c|c|c|}
\hline \multicolumn{3}{|c|}{ Impact Scoring-Degree of Focus on Risks with High and Very High Impacts } \\
\hline & Significant (Non-Linear) & Moderate (Linear) \\
\hline Very high & 16 & 5 \\
\hline High & 8 & 4 \\
\hline Moderate & 4 & 3 \\
\hline Low & 2 & 2 \\
\hline Insignicant & 1 & 1 \\
\hline
\end{tabular}

Table 2: $\quad$ Impact matrix [5].

\begin{tabular}{|c|c|c|c|c|c|}
\hline & Insignificant & Low impact & Moderate impact & High impact & Very high impact \\
\hline Budget & $\begin{array}{l}\text { Insignificant } \\
\text { Cost Increase }\end{array}$ & $\begin{array}{l}<5 \% \text { Cost } \\
\text { Increase }\end{array}$ & $5-10 \%$ Cost Increase & $\begin{array}{l}10-20 \% \text { Cost } \\
\text { Increase }\end{array}$ & $>20 \%$ Cost Increase \\
\hline $\begin{array}{c}\text { Time } \\
\text { Schedule }\end{array}$ & $\begin{array}{c}\text { Insignificant } \\
\text { delay }\end{array}$ & $\begin{array}{l}<5 \% \text { time } \\
\text { Increase }\end{array}$ & $5-10 \%$ time Increase & $\begin{array}{l}10-20 \% \text { time } \\
\text { Increase }\end{array}$ & $>20 \%$ time Increase \\
\hline $\begin{array}{l}\text { Project } \\
\text { scope }\end{array}$ & $\begin{array}{c}\text { Scope } \\
\text { decrease is } \\
\text { barely } \\
\text { noticeable }\end{array}$ & $\begin{array}{c}\text { Minor areas of } \\
\text { scope affected/ } \\
\text { Changes in } \\
\text { project features } \\
\text { with }<5 \% \text { Cost } \\
\text { Increase }\end{array}$ & $\begin{array}{l}\text { Major areas of scope } \\
\text { affercted/ Changes in } \\
\text { project features with } \\
5-10 \% \text { Cost Increase }\end{array}$ & $\begin{array}{l}\text { Major change to } \\
\text { project purpose } \\
\text { and significant } \\
\text { changes to the } \\
\text { objectives } \\
\text { which are } \\
\text { unacceptable to } \\
\text { the Project's } \\
\text { stakeholders }\end{array}$ & $\begin{array}{l}\text { Project end item is } \\
\text { effectively useles }\end{array}$ \\
\hline $\begin{array}{l}\text { Project } \\
\text { quality }\end{array}$ & $\begin{array}{c}\text { Quality } \\
\text { degradation } \\
\text { barely } \\
\text { noticeable }\end{array}$ & $\begin{array}{c}\text { No safety issues, } \\
\text { Constructionabilt } \\
\text { y Operability, } \\
\text { Maintaiability } \\
\text { deficiencies } \\
\text { approved by } \\
\text { project team }\end{array}$ & $\begin{array}{l}\text { No safety issues, } \\
\text { Constructionability, } \\
\text { Operability, } \\
\text { Maintainability } \\
\text { deficiencies require } \\
\text { CAC's approval }\end{array}$ & $\begin{array}{l}\text { Quality may be } \\
\text { made } \\
\text { acceptable } \\
\text { through } \\
\text { mitigation or } \\
\text { agreement (i.e. } \\
\text { Fact Sheet) }\end{array}$ & $\begin{array}{l}\text { Quality does not } \\
\text { meet one or all of } \\
\text { the following } \\
\text { Safety, } \\
\text { Constructionabilt, } \\
\text { Operability, and } \\
\text { Maintainbility }\end{array}$ \\
\hline
\end{tabular}

\section{Risk ranking}

A PxI matrix is developed to combine each risk's probability and impact. These matrices establish whether a risk with a certain combination of probability and impact is of high, moderate, or low priority for that objective, based on combinations of probability and impact as established by project management and other stakeholders. Two candidate matrices for threats, using the non-linear and linear impact scoring were developed, and the risk score is translated to risk ranking. Nevertheless, a score that ranges from (1-6) is low risk, from (7-14) is moderate, $15+$ is high risk.

\section{Level of control}

Level of Control (Table 3) is the influence that TB2 Renovation Program Project has regarding the outcome of the risk. 
Table 3: $\quad$ Level of control scale.

\begin{tabular}{|c|c|}
\hline High Control (4) & $\begin{array}{c}\text { ECG/ NACO, the Project Manager, has the authority to } \\
\text { control the outcome of the risk. }\end{array}$ \\
\hline Moderate Control (3) & CAC has the authority to control the outcome of the risk. \\
\hline $\begin{array}{c}\text { Minimal Control (2) } \\
\text { No Control (1) }\end{array}$ & $\begin{array}{c}\text { None of the Stakeholders can control the outcome of the } \\
\text { risk. }\end{array}$ \\
\hline
\end{tabular}

Risk Exposure will measure the overall threat of risks by assuming a risk factor. A numeric score will be used to determine a Low exposure, Medium exposure, or High exposure. The risk exposure is computed using probability and level of control. The following risk calculation expresses the overall risk exposure.

$$
\text { Risk Exposure }=(\text { Probability } \times \text { Impact }) /(\text { Level of Control })
$$

\section{Risks status}

Risks are outlined in the Risk Register (Table 4) and described in detail in Risk Control Sheets. The Risk Control Sheets identifies the risk identification number, description, owner, probability of occurrence of the undesirable event, the impact and its type (linear/nonlinear), risk level, control measures, risk exposure, contingency actions and contingency budget (if any). The risk control sheets are not allowed for publication due to confidentiality reasons. However, the Risk Register summary (Table 4) provides an overview for the project's risks and their prioritization.

\section{Summary of results}

The results of the risk managements plan, at this stage, can be summarized as follows:

- A total of twenty six (26) risks are introduced

- Twenty five (25) risks are assessed while one (1) risk is closed. The Conflict between the Cargo City project design and TB2 Apron Planning has no probability for occurrence after identifying strict limits of works and welldefined scope of coordination.

- Twenty five (25) risks have linear impact while one (1) risk has a non-linear impact, which is the Delayed Completion of the APM Station located at the new departure building of TB2. Good controls are provided for ensuring integration between TB2 and the APM Projects.

- A total of twenty four (24) risks are High Risks, while the remaining two (2) risks are Medium. 
Table 4: $\quad$ The risks associated with the construction of TB2.

\begin{tabular}{|c|c|c|c|c|c|c|}
\hline \multirow[t]{2}{*}{ Description } & \multicolumn{2}{|c|}{ Risk } & \multicolumn{2}{|c|}{$\begin{array}{c}\text { Risk } \\
\text { Exposure }\end{array}$} & \multirow{2}{*}{$\begin{array}{c}\text { Contingency } \\
\% \text { from } \\
\text { Project } \\
\text { Budget }\end{array}$} & \multirow{2}{*}{$\begin{array}{l}\text { Type } \\
\text { of } \\
\text { Impact }\end{array}$} \\
\hline & Level & Score & Level & Score & & \\
\hline Environmental regulations change & $\mathrm{H}$ & 30 & $\mathrm{H}$ & 30 & $\begin{array}{l}\text { TBD (To Be } \\
\text { Determined) }\end{array}$ & Linear \\
\hline $\begin{array}{c}\text { Permits or agency actions delayed or take } \\
\text { longer than expected }\end{array}$ & $\mathrm{H}$ & 48 & $\mathrm{H}$ & 24 & $\begin{array}{l}\text { Not } \\
\text { Applicable } \\
\text { (N/A) }\end{array}$ & Linear \\
\hline $\begin{array}{l}\text { Reviewing agency requires longer than } \\
\text { expected review time }\end{array}$ & $\mathrm{H}$ & 40 & $\mathrm{H}$ & 20 & N/A & Linear \\
\hline Late commissioning of the Project & $\mathrm{H}$ & 48 & $\mathrm{H}$ & 16 & TBD & Linear \\
\hline Delayed completion of the APM & $\mathrm{H}$ & 45 & $\mathrm{H}$ & 15 & 5 & $\begin{array}{l}\text { Non- } \\
\text { Linear }\end{array}$ \\
\hline Brown construction site & $\mathrm{H}$ & 60 & $\mathrm{H}$ & 15 & N/A & Linear \\
\hline New information required for permits & $\mathrm{H}$ & 30 & $\mathrm{H}$ & 15 & TBD & Linear \\
\hline Inaccurate traffic forecast & $\mathrm{H}$ & 36 & $\mathrm{M}$ & 12 & N/A & Linear \\
\hline $\begin{array}{l}\text { Unanticipated noise impacts / Unanticipated } \\
\text { cumulative impact issues }\end{array}$ & M & 11 & M & 11 & TBD & Linear \\
\hline Inaccurate contract time estimates & $\mathrm{H}$ & 42 & M & 10.5 & N/A & Linear \\
\hline $\begin{array}{c}\text { New information after Environmental } \\
\text { Document is completed may require re- } \\
\text { evaluation or a new document }\end{array}$ & $\mathrm{H}$ & 30 & M & 10 & TBD & Linear \\
\hline $\begin{array}{c}\text { Change requests due to differing site } \\
\text { conditions }\end{array}$ & $\mathrm{H}$ & 39 & M & 9.75 & 0.5 & Linear \\
\hline $\begin{array}{l}\text { Improper IT interfacing between TB2 and } \\
\text { TB3 }\end{array}$ & $\mathrm{H}$ & 36 & M & 9 & TBD & Linear \\
\hline $\begin{array}{l}\text { Conflict between the Cargo City project } \\
\text { design and TB2 Apron Planning }\end{array}$ & $\mathrm{H}$ & 34 & M & 8.5 & N/A & Linear \\
\hline Insufficient coordination with the tenants & $\mathrm{H}$ & 24 & $\mathrm{M}$ & 8 & TBD & Linear \\
\hline $\begin{array}{l}\text { Delayed commissioning of the new } \\
\text { chlorination station }\end{array}$ & $\mathrm{H}$ & 32 & M & 8 & N/A & Linear \\
\hline Stakeholders request late changes & $\mathrm{H}$ & 30 & $\mathrm{M}$ & 7.5 & 1 & Linear \\
\hline New or revised design standards & $\mathrm{H}$ & 27 & $\mathrm{~L}$ & 6.75 & 4 & Linear \\
\hline Inaccurate as-built drawings & $\mathrm{H}$ & 24 & $\mathrm{~L}$ & 6 & N/A & Linear \\
\hline $\begin{array}{l}\text { Existing utilities not defined and in conflict } \\
\text { with construction }\end{array}$ & $\mathrm{H}$ & 24 & $\mathrm{~L}$ & 6 & 0.125 & Linear \\
\hline $\begin{array}{l}\text { Insufficient or limited construction or staging } \\
\text { areas }\end{array}$ & $\mathrm{H}$ & 24 & $\mathrm{~L}$ & 6 & N/A & Linear \\
\hline Increase in material cost due to market forces & $\mathrm{H}$ & 21 & $\mathrm{~L}$ & 5.25 & 10 & Linear \\
\hline $\begin{array}{l}\text { The design is incompatible with ICAO and } \\
\text { ECAR }\end{array}$ & $\mathrm{H}$ & 18 & $\mathrm{~L}$ & 4.5 & N/A & Linear \\
\hline Design Errors & $\mathrm{H}$ & 18 & $\mathrm{~L}$ & 4.5 & N/A & Linear \\
\hline $\begin{array}{c}\text { Environmental clearance for staging or } \\
\text { borrow sites required }\end{array}$ & $\mathrm{H}$ & 18 & $\mathrm{~L}$ & 4.5 & N/A & Linear \\
\hline $\begin{array}{c}\text { Contamination of existing ground or building } \\
\text { materials }\end{array}$ & M & 12 & $\mathrm{~L}$ & 3 & N/A & Linear \\
\hline
\end{tabular}

After proposing control measures, seven (7) risks remained High level, while the remaining risks was risks were distributed between Medium (10 risks) and Low Levels (9 risks). Tentatively, an amount pursuant to $20.6 \%$ of the project's construction cost is determined as a contingency budget. This contingency budget is recommended to be increased to $22 \%$ of the Project's Budget as CAC's contingency. It should be noted in certain cases, no contingency budget was provided and was denoted as "N/A: Not Applicable". In these cases the risk is totally born by other parties, including the Engineer and the Contractor, where 
the contingency budget is accounted for in their contracts. In some other cases, the project team was not able to estimate the contingency budget, and these risks contingency budget are denoted by "TBD: To Be determined"; however, it is believed that these risks contingency budget is covered by the selected $22 \%$ value.

\section{Conclusions}

This presented risk management plan provided a comprehensive approach to manage and control foreseen risks that could have a negative impact on the Renovation Program of TB2 Project. The approach also provided control measures that shall be adhered-to during the project's life cycle in order to minimize the exposure to the foreseen risk and eliminates, to great extent, the management by crisis approach. Also, the presented mechanism shall serve in reporting new unforeseen risks that shall be documented and analyzed by the project's stakeholders. By virtue of the adopted approach, a contingency budget estimated at $20.6 \%$ of the project's construction cost could have been assessed and allocated for treating risks in case of occurrence. It was recommended by the consultant to raise this contingency budget to $22 \%$ to absorb part of the unforeseen risks in case of occurrence.

\section{Acknowledgements}

The encouragement and support of General Engineer Ibrahim Manaa, Chairman of EHCAAN, General Pilot Fathy FathAllah, Vice Chairman of EHCAAN, and General Pilot Hassan Rashed, Chairman of CAC, have stimulated much of our recent thinking about TB2 design.

\section{References}

[1] CAC, www.cairo-airport.com

[2] IATA, Airport Development manual, 9th edition, 2004.

[3] TB2 Renovation Program Preliminary Design Report, 2009, Technical Report Prepared by ECG/ NACO.

[4] Project Risk Management Handbook, June 26, 2003, Rev 0, Office of Project Management Process Improvement, 1120 N Street, Mail Station 28, Sacramento, CA95814, www.dot.ca.gov/hq/projmgmt

[5] Project Risk Management Handbook, Second Edition, Revision 0, May 2, 2007, Office of Statewide Project Management Improvement (OSPMI), $1120 \mathrm{~N}$ Street, Mail Station 28, Sacramento, CA 95814, www.dot.ca.gov/hq/projmgmt.

[6] Wideman, R. Max. Project and Program Risk Management, A Guide to Managing Project Risks and Opportunities, A Publication of the Project Management Institute, 1992. 